\title{
Teachers' Professional Development and Education Innovation Under the Background of "Internet Plus Education" in Colleges
}

\author{
Qingtao Liu \\ Baicheng Normal University, Baicheng, Jilin, 137000, China \\ email: bcsmh@163.com
}

Keywords: Internet Plus Education; College Teachers; Professional Growth; Educational Innovation

\begin{abstract}
The new era Internet plus education has brought new development direction for the teaching of higher education. College teachers are faced with both opportunities and challenges. College teachers need to adapt to the new background for professional growth and educational innovation. This article starts from the influence of Internet plus education background, probes into the teachers’ professional development and education innovation strategy in colleges.
\end{abstract}

\section{A Brief Introduction of "Internet plus Education"}

With the development of modern science and technology, China has entered the "Internet plus" strategic development stage."Internet plus" refers to the depth integration of the innovation in the field of Internet and various fields of modern economic and social development, and promote efficiency, organizational change and technological progress. Then, to further improve the modern real economy ability and innovation ability, society eventually form a new form of Internet infrastructure and the innovative elements of the broader integration of modern economic and social development [1]. One of its main features is the leap from information technology to data technology. In simple terms, "Internet plus" is connected through the Internet to learn in every aspect of your life, this is the attribute of "plus".

"Internet plus education" is a combination of Internet and education. Through various forms of online education, make the education from closed to open, breaking the monopoly of knowledge, teaching to break the barriers in space and time. Teachers can use video or network communication to provide online education courses, at any time, any place can be to teach the course, and students are not like the traditional model, only in the field of classroom lectures, classes of students can even cross regional, cross-border, according to their own standards and preferences, choose to listen to the class who, at what time courses and so on.

The rise of "Internet plus education" has brought a profound impact for college teachers. For college teachers, quickly adapt to the new mode of education, closely follow the pace of the times, accelerate self-improvement, professional development and education innovation, is the key to fulfill their social responsibilities and functions of teachers' occupation.

\section{"Internet plus Education" Brings the Change of Teaching Mode}

Changes in Education. The rapid development of the Internet has brought new technology. Produced many new mode of education and form in education, such as online school, MOOC, self organizing learning, open class, game based learning. Classroom education in the school, also produced the flipped classroom, creating classroom, mobile learning a variety of new classroom teaching mode. With the continuous development of robot technology, the team at home and abroad with the basic function can play football and in gradually to pick the ball function development. Pick the ball design break through the traditional 2D game model, this makes robot can directly hit the opponent ball and don't have to go around, this simplified decision-making, increase attack and breakthrough are quite useful. But because of the limits of the robots, how to make robots in the limited space in both playing and picking the ball is a big test of the structure design.

Change of Teaching Environment. Education will be moved into the process of the Internet in 
"Internet plus education", the entity school field classroom teaching mode is no longer necessary to master environmental knowledge. We can say that in the world of anyone who wanted to accept the education, find the related courses in the network. The World Education Innovation Summit issued the "2030 school" the investigation report, which mentioned that "the future is no longer a student from local schools, theoretical knowledge on the contrary, it will become a kind of social environment, the students accept the guide here, and student interaction, collaborative learning, access to a variety of skills, in order to adapt to future occupation career" [2].

The Change of Teaching Development Task. Education and teaching environment affects teaching comprehension and teaching concept of teachers. With the deepening of Internet plus education, teacher's teaching task will be changed. Creation is to guide students to learn from the professor the student knowledge, teaching content from traditional textbooks into educational resources, teaching space from the school classroom into the network, at the same time in the family, school, social education and within collaborative community.

\section{The Advantages and Challenges of Internet plus Education in Colleges and Universities}

The Importance and Advantages of Internet plus Education in the Development of Teachers in Colleges and Universities. Internet plus education has considerable advantages in the development of university teachers. The diversity of network information make teachers can easily get all kinds of resources from the network; also can communicate on the Internet. In this way, teachers are unable to improve their professional skills. There is a lack of communication that can be conducted only at seminars, and in any field, any professional teacher can explore each other through the Internet, offering insights into professional growth and educational innovation. The high quality resources in the network and the open peer relationship make the teachers have more resources to grow, and through the network to form a learning community, it is also more convenient for teachers to share experiences with each other and share resources.

"Internet plus Education" Brought Demands and Challenges for Teachers. With the arrival of "Internet plus education" mode, not only has the superiority, is also a challenge. For college teachers, young teachers usually are more familiar on the Internet, can actively accept advanced ideas. But the group of university teachers for the old professor number, because older, accept new things slightly slower than the young group, often in an "Internet plus" there are some disadvantages from information to large change practice mode the. Then you need to renew the idea, in the context of the Internet as much as possible to play the role of education, transform challenges into opportunities.

The new educational background of teachers' demands and challenges are as follows: one is that teachers need to continue to update the concept of education; the Internet will be used in the education. Two teachers should change their roles and status, to adapt to the change of teaching mode as soon as possible, change from teaching mode to fixed time online and offline hybrid teaching mode three. In their own ascension and teaching as much as possible the use of fragmented learning time, learning time is more flexible. Four teachers should possess information literacy. In the professional core competence, not only to master the method of teaching knowledge and content knowledge, but also need to have technical knowledge, technical knowledge on here. Refers to the ability of network information technology teachers.

\section{The Strategies and Approaches of Teachers' Professional Development on the Internet plus Education Background}

Study: Using Network Communication Platform to Grow and Develop. Generally speaking, teachers' professional grows through learning, research and practice. Under the background of the Internet plus education, we will be the advantage of information technology and network into learning and work, make full use of information resources and digital means to broaden the growth path, realize the professional growth.

First, teachers can conduct training through the network, such as network training, school-based 
training at all levels of training. According to their own needs, by use of network resources, through the open class, Mu class, teachers specialized communities, forums and other sharing and education platform, learning under the background of Internet education theory. Teaching skills and teaching methods. Absorb excellent experience among peers, and actively carry out exchanges, the right to face their own doubts and problems in teaching, participate in online discussion lesson [3].

Second, in the learning process, teachers should pay attention to their own professional knowledge constantly, in order to learn more about the teaching content, to provide better teaching activities for the students, but also pay attention to their teaching skills, grasp the network exchange opportunities, through the blog, personal blog to form a study circle, the application of We Chat public number, QQ space circle of friends, Sky Drive, and other resources communication platform to carry out learning how to communicate with teachers, achieve ideal teaching effect in the teaching process.

Third, make full use of time for informal learning. In addition to the training and study various courses, in informal learning approach is also suitable for the growth of absorption of college teachers, such as the Internet to participate in the salon, reading activities, network chat and reflection, this way of learning is more consistent with the characteristics of adult learning, to meet the needs of teachers' professional development and lifelong learning. Moreover, informal learning is oriented to problems and needs, targeted natural learning, can not only save time, but also can reduce the cost, with a positive attitude to actively participate in learning, but also conducive to the professional development of teachers.

Research: Leading Practice by Scientific Research. College Teachers' professional growth always cannot do without the research projects and experimental research, with the development of the Internet, also appeared in the teaching of many new problems, which requires teachers to research on exploration of new educational technology and the new mode of teaching, deepen the education mode Internet plus education under the background of understanding, will work the problems encountered in teaching as a subject for study, in the study, the research in teaching, constantly update the concept of education, the Internet will bring professional growth to teaching them.

Practice: Promoting Professional Growth through Practical Experience. The Internet and daily education teaching activities combined, actively participate in various exhibitions and contests, competitions, such as micro class competition, learning space competition, "a teacher a lesson, a lesson a teacher" showing off activity and so on, through practice to hone their own, listen to the opinions of others, also want to carefully watch the other teachers' work, to absorb the essence, continue to strengthen themselves.

When the heavy burden in the teaching, we must use artificial intelligence under the background of Internet management in the information age, teaching evaluation, the new service model, basic science foundation, a new system of technology, theory and methodology on the basis of [4]. Enrich their way of reasonable utilization of the integration of the Internet, the construction of more new teaching service system. By providing efficient, intelligent information, teaching service, free from work, rely on the Internet to provide teaching service consultation, supervision and evaluation in their effort, improve the teaching level, promoting professional growth.

\section{Exploring the Innovation of University Teachers' Education under the Background of Internet plus Education}

Teachers Play a Leading Role in Educational Innovation. "National long-term education reform and development plan (2010-2020)" clearly shows that higher education is responsible for the major task of cultivating advanced talents, developing science and technology culture and promoting the modernization, the fundamental purpose of education reform and development is to improve the national quality and improving the quality of education is the core task of education reform and development. The integration of the Internet technology and professional teaching will promote the reform and innovation of higher education, and the key to the realize the educational development strategy is the teachers, it is the key to decide the success or failure of the reform of higher 
education that mobilizing the enthusiasm and initiative of teachers' participation in education innovation, giving full play to the leading role of teachers, and establishing a high-quality teacher team who can carry out reform and innovation of information on the internet teaching faculty[5].

Through the education reform and innovation, teachers in Colleges and universities can carry out all-round innovation of teaching process, including curriculum design, teaching methods, teaching objectives and teaching methods and other aspects, and develop science culture to promote social modernization by cultivate high-quality innovative talents.

The education innovation of college teachers can be carried out in various ways, such as the construction of hierarchical teaching system, the construction of teaching support system, the construction of educational practice teaching center, the innovation of education methods and so on.

Constructing a Hierarchical Teaching System. Hierarchical teaching system is the innovation of education for students' lack of practical experience, especially in the education experimental courses, and through practice students can grasp the specific practices and have the ability to practice innovation.

The teachers need to combine the classroom teaching with the experimental training through the online and offline teaching activities. In the classroom, teachers can carry out part of the teaching activities of the case demonstration, the simulation process and tell about the basic theoretical knowledge. Online under the guidance of teachers, students can verify the experiment, according to the teaching objectives experiment can be divided experimental verification and self training, comprehensive design schemes, teachers should set the task ahead of time, let the students into groups, respectively undertake independent tasks, refer to literature through the Internet by themselves, and even the design experimental program. Because of the large number of data on the Internet, the result of each student will be different, and then you can provide learning materials and supporting materials for students by the network information technology, share the results of their experiments through the network preview and exchange.

The Construction of Support System of Teacher Education Practice Teaching and Teaching Center. It is the only way for educational innovation to use Internet to integrate resources, build practical teaching support system and teaching center. The teaching support system can include three parts, namely, the campus training platform, the practice base outside the campus and the virtual platform training. It mainly uses the resources of all aspects and takes the project as the link to form a good software and hardware environment, with the help of the power of the Internet, with the center of basic education resources, the digital network micro brother platform, informatization teaching form of teacher education, remote internship platform as the foundation, build a unified platform for virtual training teaching, which not only provides an effective means of communication for the internal and external training platform, but also provides teaching aids or alternative methods for teachers' practical teaching in different teaching links. By constructing the demo video library, learning of the basic skills from the classroom gradually can be transferred to the virtual platform, be transfered from lessons outside, and building a virtual simulation platform of teacher education and training to gradually open and share the educational resources through the project library [6].

Constructing Educational Innovation Model Using the Internet plus. In the specific level, under the Internet education background teachers can innovate education mode directly, for example, using the new forms of communication, such as Mu rain, the classroom, We Chat public number, learning app, teaching methods by the use of fragmented, teaching content will be divided into small points, made into a few minutes or ten minutes or the short video for sharing to students, students can use fragments of time to study or to expand their knowledge. It can also carry out a course from entry to advanced learning by organizing the punch group, such as "MOOC room", "planets as early as possible " and so on, teachers can learn experience, innovate teaching ideas, teaching objective and teaching form, and make the teaching contents more close to their life, with the spirit of the Internet to package their teaching content, teaching is done by the way of making students more easily understand and accept. In addition to the innovation of education for students, teachers also need to enhance themselves through the organization of learning group, by means of 
the Internet, to obtain the advantages of information literacy training and information retrieval ability with the use of the Internet resources, and the form the innovative education and teacher training of multi platform in the teacher training form, and in the new educational background enrich themselves and improve their professional ability and continue to carry out the education innovation.

\section{References}

[1] Han Zhen. "Journal of Internet plus education under the background of University Teachers' professional development [J]. North China University of water conservancy and hydropower (SOCIAL SCIENCE EDITION), 2015,31 (6): 99-101.

[2] Zhang Yan. Strategies and approaches for teachers' professional development in the information age [J]. Forum on Teacher Education, 2015,28 (4): 15-17.

[3] Ji Changqing, Song Lin. Research on teacher professional development under the new Internet [J]. Chinese Science and Technology Information, 2010 (20): 256-257.

[4] Chen Jing, Zhao Junfeng. "Internet plus education" of the University Teachers' professional development of [J]. Education Theory and Practice, 2016 (27).

[5] Hu Jianying on "Internet plus teachers in Colleges and Universities under the background of" leading role in education innovation in [J]. Mass Art, 2016 (8): 230-230.

[6] Li Xiaozhi, Yang Gang, et al. The training mode of innovative talents for teacher education based on Internet [J]. Modern Educational Technology, 2015, (25): 121-125. 